\title{
Intracranial stimulation and one-drop licking in the rat
}

\author{
KENNETH P. von der PORTEN \\ University of New Hampshire, Durham, New Hampshire 03824
}

\begin{abstract}
The present study examined the effects of intracranial stimulation (ICS) of the lateral hypothalamic area $(\mathrm{LH})$ on the lick response of the rat. Rewarding stimulation and/or a drop of water was presented contingent on a lick. Three rats were run on a three-ply multiple schedule. On separate components, licks were reinforced with water, water plus ICS, or ICS alone. For each component, the total number of licks was recorded as well as measures of the burst of licking that occurred after water reinforcement. Initially, nine ICS intensities were used from threshold (T) to threshold plus $400 \mu \mathrm{A}(\mathrm{T}+400 \mu \mathrm{A})$. All animals were tested while water deprived, receiving their daily 12-cc ration after the testing session. Then the animals were retested at two ICS intensities (T and T $+200 \mu \mathrm{A}$ ), receiving their daily 12-cc ration of water either $1 / 2 \mathrm{~h}$ before being tested or at the end of the session. ICS intensities above threshold decreased the rate of responding when the stimulation was combined with water, both in terms of emitted and elicited licking. The operant lick rate for ICS alone was always lower than the lick rate for water alone or for water plus ICS. Water deprivation increased licking during the water component, marginally increased licking in the water-plus-stimulation component, and did not increase licking in the stimulation-only component.
\end{abstract}

The one-drop licking paradigm (Hulse, 1960) used in the present experiment allowed an independent assessment of what has been called by Hulse (1967): emitted or operant licking and elicited or reflexive licking. Reflexive licking is in response to a fluid stimulus on the tongue. In the former case, operant licking occurs in a manner more closely resembling other types of operant behavior, in that an animal licks in order to obtain the fluid reinforcement.

This technique allows one to look at these two types of behavior within a single session, holding constant motivational and other factors. Also, when the single drops are programmed on an interval schedule of reinforcement, the number of licks and reinforcement probability can be manipulated independently.

The reflexive responding normally occurs in a burst of licks and is defined as those licks occurring immediately after the delivery of a reinforcing stimulus to the tongue. The duration of the burst is defined as the time from stimulus delivery until an interlick interval occurs greater than some criterion. A measure of burst length can be obtained either as a function of the number of licks it contains or as a function of the duration (in seconds) of the burst. A measure of the rate of licking within the burst can be obtained by dividing the number of licks it contains by its duration.

Operant licks are then defined as those licks occurring in the session that are nonburst licks. Nonburst licks are those licks occurring after a burst ends and before the delivery of another stimulus (fluid drop). These can be divided by the nonburst time of the session to yield an operant or nonburst lick rate (licks/sec).

This testing procedure allows a test of one of the assumptions of the incentive theory of rewarding intracranial stimulation (ICS) of Trowill, Panksepp, and Gandelman (1969). This theory states that responding for rewarding ICS should be qualitatively the same as responding for any other type of positive incentive stimulus, as long as the conditions under which both are delivered are carefully equated. Of particular importance is the drive state of the animal and the temporal relationship between the response and the delivery of the reinforcer. If rewarding ICS were identical to a water drop on the tongue, then combining the two should result in an increase in operant responding. Also, licking for either water or ICS alone should be similar.

A second purpose of this experiment was to determine the generality of the increase in motor excitability reported by Wayner (1970) and White and Wayner (1972), with animals responding for positive ICS to the LH. Wayner (1970) has provided some evidence that ICS to the LH which is capable of eliciting stimulus-bound behavior results in an increase in motor excitability. Directly related to the present experiment, White and Wayner (1972) found an increase in the rate at which a rat would lick for water (when drinking had been induced by the ICS) when the intensity of ICS was increased. Although the neural circuits of the $\mathrm{LH}$ which underlie both stimulus-bound eating and drinking and rewarding ICS effects are generally thought to coincide, no mention was made whether these animals would 
also self-stimulate. It would be expected that if the ICS in this area did increase motor excitability, then a measure of reflexive licking, i.e., burst size or rate of licking within the burst should increase with increases in ICS intensity.

\section{METHOD}

\begin{abstract}
Animals
Three Wistar male albino rats (approximately $475 \mathrm{~g}$ ) that had bipolar twisted stainless steel electrodes implanted in their brains were used.

\section{Surgery}

The electrodes (wire diameter, $.24 \mathrm{~mm}$ ) were implanted unilaterally while the animals were under sodium pentobarbital anesthesia (Nembutal, $80 \mathrm{mg} / \mathrm{kg}$ ). Electrode coordinates were $3.00 \mathrm{~mm}$ posterior to bregma, $1.50 \mathrm{~mm}$ lateral to the midline, and $8.50 \mathrm{~mm}$ below the surface of the skull, with lambda and bregma in the same horizontal plane.
\end{abstract}

\section{Apparatus}

All testing was done in an aluminum and Plexiglas box $(26 \times 26 \times 36 \mathrm{~cm})$ located in a sound-attenuated chamber. A Plexiglas drinking tube was located at one end of the box, $4.5 \mathrm{~cm}$ above the grid floor and $12.5 \mathrm{~cm}$ from each side of the box.

A Harvard Apparatus syringe pump driven by a Ledex stepping motor, similar to that used by Hulse (1960), provided the water reinforcement. Each operation of the pump delivered $0.007 \mathrm{cc}$ of water. The water was then automatically withdrawn from the drinking tube in order to prevent reinforcement of subsequent licks. A Plexiglas plate was positioned directly in front of the drinking tube. A $1.0 \times 5 \mathrm{~cm}$ slot in the plate allowed only recording of the contact made by the rat's tongue. The tube was positioned approximately $.5 \mathrm{~cm}$ behind the slot. Simultaneous contact with the grid floor and a small brass rod in the drinking tube completed the circuit of a Scientific Prototype drinkometer. During the brief period of reinforcement presentation (both ICS and water), both the grid floor and the drinking tube were switched out of the circuit by a relay.

Electrical stimulation consisted of a .10-sec train of biphasic alternating positive and negative square-wave pulses (pulse width, $8.0 \mathrm{msec}$ ) at a frequency of $60 \mathrm{~Hz}$.

\section{Procedure}

Animals were initially trained to press a bar for ICS delivered on a continuous reinforcement (CRF) schedule. An approximate threshold was obtained by finding the intensity at which the animals would continuously barpress, but at the lowest possible rate. This was done by lowering the ICS intensity in $10-\mu \mathrm{A}$ steps until the animal stopped responding. After the animal stopped responding, the intensity was then increased in $20 \mu \mathrm{A}$-steps until the animal resumed responding. Priming stimulations were given if necessary. Threshold was defined as a value $10 \mu \mathrm{A}$ below the intensity at which the animal began responding.

The animals were then put on a water-deprivation regimen by restricting their daily water intake to $12 \mathrm{cc}$. They were then trained to lick for water in the one-drop licking apparatus, receiving their daily water after the session ended. A CRF schedule of water delivery was used at first; later, only occasional licks were reinforced with water drops. The animals' lick rates stabilized quickly on a variable-interval 15 -sec schedule (VI 15' ') for water drops. This was then expanded to a three-ply multiple schedule. On one component, licks were reinforced on a VI 15' ' schedule with a water drop only $(W)$. Licks were reinforced on the second component on a VI $15^{\prime \prime}$ schedule with a water drop and simultaneously a .10 -sec train of ICS $(W+I)$. The third component was identical to the preceding two, except that licks were now reinforced with ICS only (I). Each individual component had a distinct tone and light associated with it signaling the animal which component he was in. Each component lasted $10 \mathrm{~min}$ and was separated by a 3-sec blackout period during which the tone and light were off. Licks during this period were not reinforced or recorded.

Animals were initially tested on the three-ply multiple schedule at threshold plus $200 \mu \mathrm{A}(\mathrm{T}+200 \mu \mathrm{A})$ for 2 days. The intensity was then increased in $50-\mu \mathrm{A}$ steps to $\mathrm{T}+400 \mu \mathrm{A}$, then decreased in $50-\mu \mathrm{A}$ steps to $\mathrm{T}$, then increased in $50-\mu \mathrm{A}$ steps again to $\mathrm{T}+$ $200 \mu \mathrm{A}$. This procedure was employed to determine the effects of a large range of ICS intensities. The order of presentation of the $\mathrm{W}$ and $\mathrm{W}+\mathrm{I}$ components was alternated so that, at each intensity, there was data for each of the two combinations, $W / W+I / I$ and $W+I / W / l$. During this phase of the experiment, the animals were restricted to $12 \mathrm{cc}$ of water daily, which was given after the testing session.

After this preliminary phase, the animals were tested at two ICS intensities, $\mathrm{T}$ and $\mathrm{T}+200 \mu \mathrm{A}$, while either water deprived or prewatered their daily 12 -cc ration of water. The $\mathrm{W}$ and $\mathrm{W}+\mathrm{I}$ components were again alternated daily. The animals were first tested at $\mathrm{T}+200 \mu \mathrm{A}$ with each of the two orders of component presentation (one each day) and received their daily $12 \mathrm{cc}$ of water after the session. Then, while still at $\mathrm{T}+200 \mu \mathrm{A}$, they were given their 12 -cc ration $1 / 2 \mathrm{~h}$ before the start of the session, and again run for 2 days, with each order of component presentation. Next, they were run at $T$ for 2 days, with the two orders, with their water given after the session. Finally, they were run at threshold ICS for the last 2 days, receiving their water before the session.

\section{Measures}

The total number of licks, the total number of bursts, and the duration and number of licks contained in the bursts were recorded for each component of the multiple schedule. A burst of licks was defined as those licks occurring after reinforcement delivery that were separated by an interlick interval not greater than 340 msec. This interval was found by Hulse and Suter (1970) to reliably signal the end of a burst of licks made by a rat in the one-drop licking apparatus.

From these measures, the size of the burst of licking following reinforcement delivery, both as a function of the number of licks it contained (average burst size $=$ total licks in bursts/total number of bursts) and burst duration in seconds (average burst duration = total burst durations/total number of bursts), and the rate of licking within the bursts in licks/sec (burst lick rate $=$ total licks in burst/total burst durations) could be calculated. Finally, all nonburst licks were divided by the nonburst time to yield the nonburst or operant lick rate (licks/sec).

\section{RESULTS}

The results of this experiment indicate that licking for ICS is clearly distinguishable from licking for water. First, there was a clear difference in the pattern of responding immediately following reinforcement delivery. Rats licking on a partial reinforcement schedule for single water drops typically gave a burst of licks that decayed with time after the water delivery (Hulse, 1960, 1967; Hulse \& Suter, 1970). Rats licking for ICS alone did not show a reflexive burst of licking in response to the stimulation. That is, after the first or second lick, pauses of $340 \mathrm{msec}$ or longer occurred. For this reason, burst measures for the I component are omitted.

Second, for nonreflexive or operant licking, the combination of ICS and water reinforcement decreased the rate of licking in that component from 
the rate of licking in the $\mathrm{W}$ component (Figures 1, 2, and 3). The operant licking for ICS alone was paradoxically lower than licking for water alone. For all three animals, there was a rather shallow response rate/intensity function for operant licking in the I component (Figures 1-3). Also apparent during this initial phase was the reduction in the size of the burst of licking in the $\mathrm{W}+\mathrm{I}$ component when compared to the W component (Figures 4-6). Across all ICS intensities, the decrement in burst size was either fairly constant (W-54, Figure 6) or varied inversely with intensity (W-51, Figure 5).

It was possible that the higher intensity ICS was acting merely to interrupt the licking in the $\mathrm{W}+\mathrm{I}$ component. Thus, very short bursts would be averaged into the total burst time, accounting for the decreased average burst duration. To determine if, in fact, this was happening, a parallel entry printout counter was used to record individual licks within the bursts after the delivery of a reinforcer and the durations of the individual bursts. All bursts of three licks or less were then eliminated for both the $\mathrm{W}$ and $\mathrm{W}+\mathrm{I}$ components, and the average burst size computed (licks/burst, Figure 7). The animals were making multilick bursts in the $\mathrm{W}+\mathrm{I}$ component, but of smaller size than in the $\mathrm{W}$ component.

In the second phase of the experiment, the effects of water deprivation were compared with two intensities of ICS. For operant licking, water deprivation had the greatest effect on responding in the W component (Figure 8), less effect on the W + I component, and no effect on the I component. ICS intensity had the greatest effect on responding in the I component, with significantly higher response rate at $\mathrm{T}+200 \mu \mathrm{A}$ than at threshold intensity $(\mathrm{p}<.05$,
Newman-Keuls test). The $\mathrm{W}+\mathrm{I}$ component was affected less by ICS intensity, and the $\mathrm{W}$ component was affected least of all. Since the animals were receiving only water in the $\mathrm{W}$ component, no effect of ICS intensity should be expected. It should be noted, however, that when the animals were nondeprived and in the $\mathrm{W}$ component, they licked significantly less ( $p<.05$, Newman-Keuls test) at $\mathrm{T}+200 \mu \mathrm{A}$ than when water-deprived and at $\mathrm{T}+200 \mu \mathrm{A}$. Apparently they were affected by the higher stimulation intensities on the other components.

The deprivation manipulation did not affect reflexive licking in either the $W$ or the $W+I$ components. Therefore, the effects of ICS intensity on burst duration for the $\mathrm{W}$ and $\mathrm{W}+\mathrm{I}$ components were averaged across the deprivation condition (Figure 9). The increase in burst size at threshold intensity in the $\mathrm{W}+\mathrm{I}$ component was not significantly different from the mean at threshold intensity in the $\mathrm{W}$ component. The decrease in burst duration in the $\mathrm{W}+\mathrm{I}$ component at $\mathrm{T}+200 \mu \mathrm{A}$ also failed to reach statistical significance, although the Intensity by Reinforcement interaction was significant (ANOVA, $\mathrm{p}<.05$ ). The apparent decrease in burst size with increased ICS intensity was completely consistent with the results of the preliminary testing (Figures 4, 5, and 6).

The results of the histology showed that all electrodes were located in the LH area (Figure 10).

\section{DISCUSSION}

The results of this experiment indicate that adding ICS to water reinforcement does not increase the

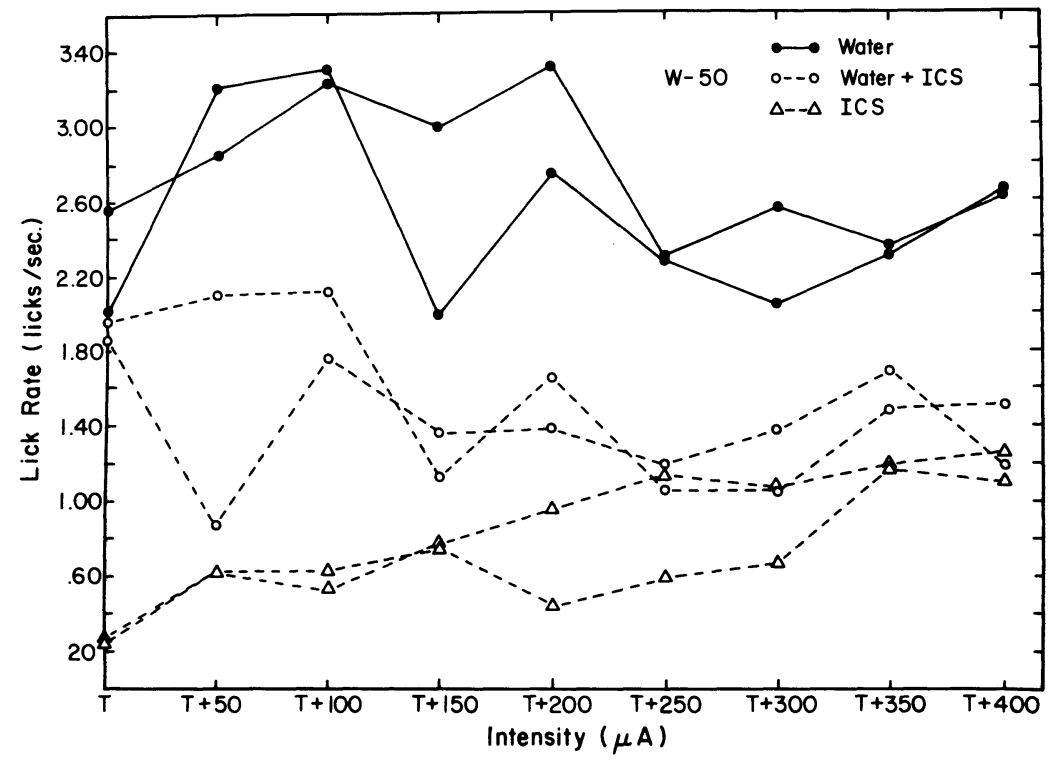

Figure 1. Nonburst lick rate (licks/sec) for W-50 from threshold (T) to threshold plus $400 \mu \mathrm{A}(\mathrm{T}+\mathbf{4 0 0} \mu \mathrm{A})$ for each component of the multiple schedule. 


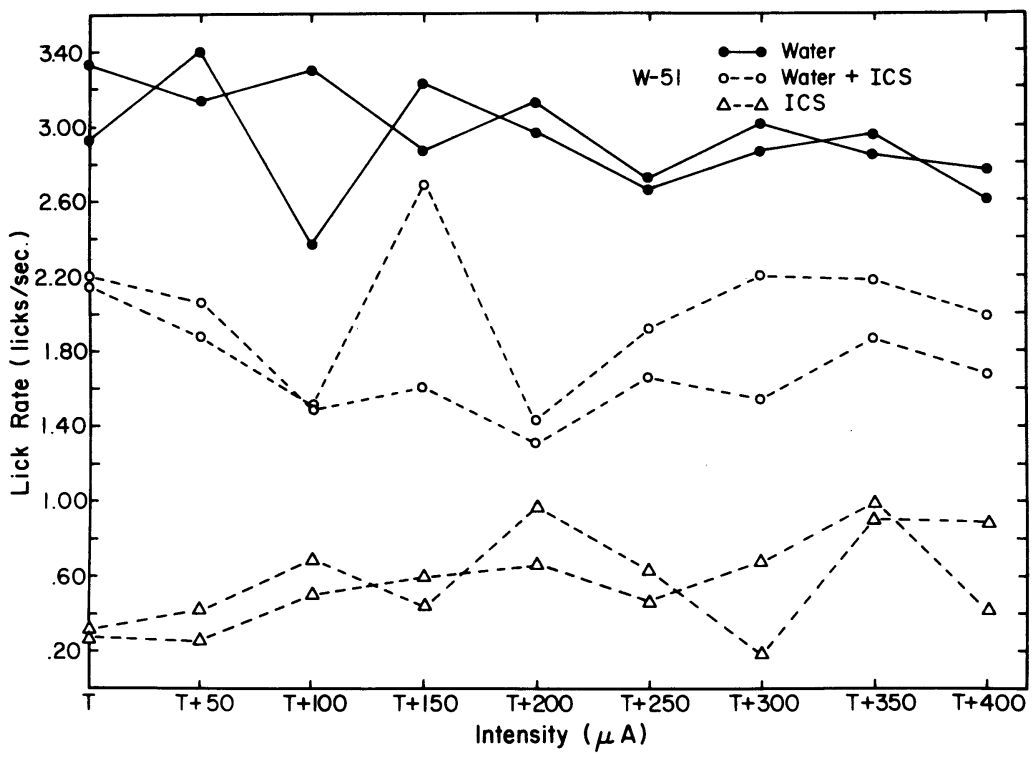

Figure 2. Nonburst lick rate (licks/sec) for W-51 from threshold (T) to threshold plus $400 \mu \mathrm{A}(\mathrm{T}+400 \mu \mathrm{A})$ for each component of the multiple schedule.

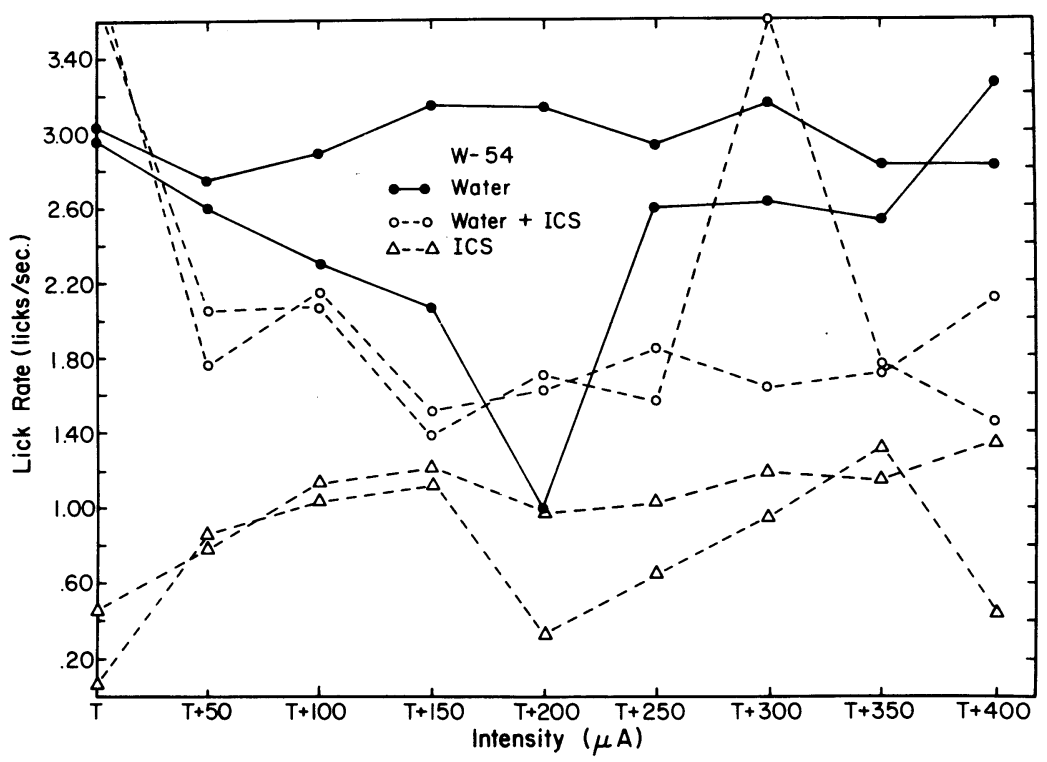

Figure 3. Nonburst lick rate (licks/sec) for W-54 from threshold (T) to threshold plus $400 \mu \mathrm{A}(\mathrm{T}+\mathbf{4 0 0} \mu \mathrm{A})$ for each component of the multiple schedule.

reflexive lick rate to delivery of a water drop onto the tongue (Figures 4, 5, 6, 7, 9). Although, at threshold, there was a slight facilitory effect on burst size (Figure 9), this was not significant $(p>.05$ ). Such a facilitation would be predicted from theories that stress the affect of ICS on the motor system of the CNS. Wayner (1970) has theorized that electrical stimulation of the LH area increases motor excitability. His theory equates reinforcement value with response probability in a Premackian sense $(1970$, p. 1320). Wayner has argued that more motor units are activated by the same afferent input when the LH area is electrically stimulated. It is for this reason that an animal gives a supernormal response to otherwise normal environmental stimuli, e.g., food, water, or a wood block in a typical stimulusbound behavior screening situation. This could also explain how an animal responds for rewarding ICS. The stimulation-induced increase in motor excitability would increase the probability of responding to the bar, since the ICS results directly from this behavior.

The present data do not support this (1970) hypothesis. If ICS increased the number of motor 


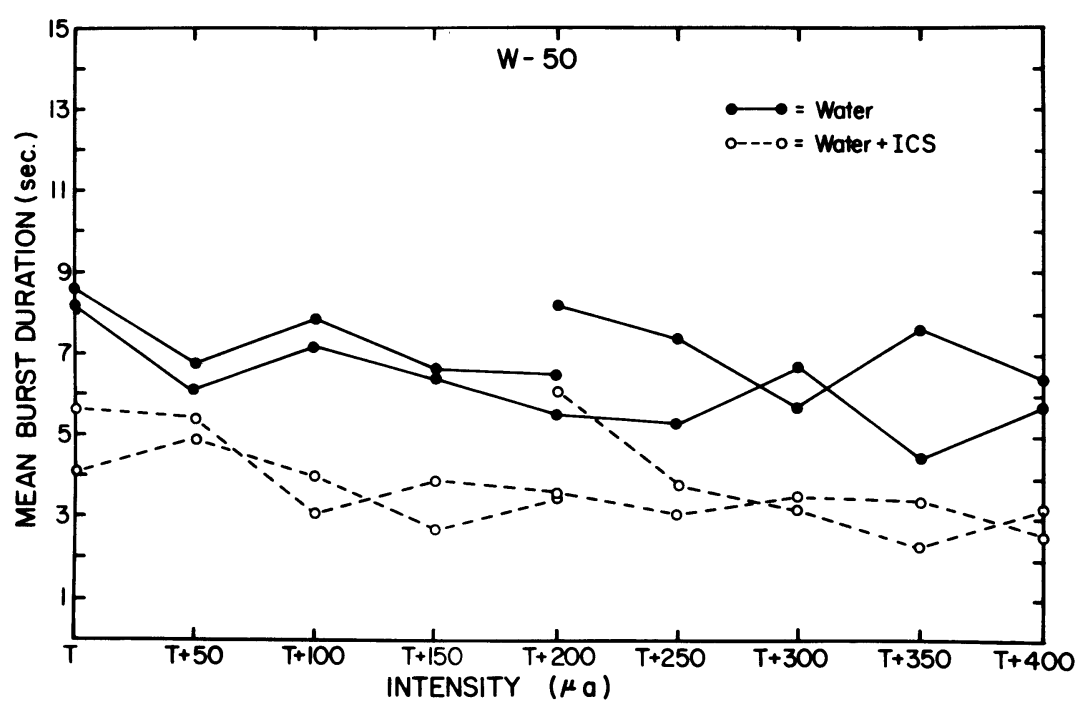

Figure 4. Burst duration (in seconds) for W-50 from threshold (T) to threshold plus $400 \mu \mathrm{A}(T+400 \mu \mathrm{A})$ for the water $(\mathrm{W})$ and water plus ICS $(\mathrm{W}+\mathrm{I})$ components of the multiple schedule.

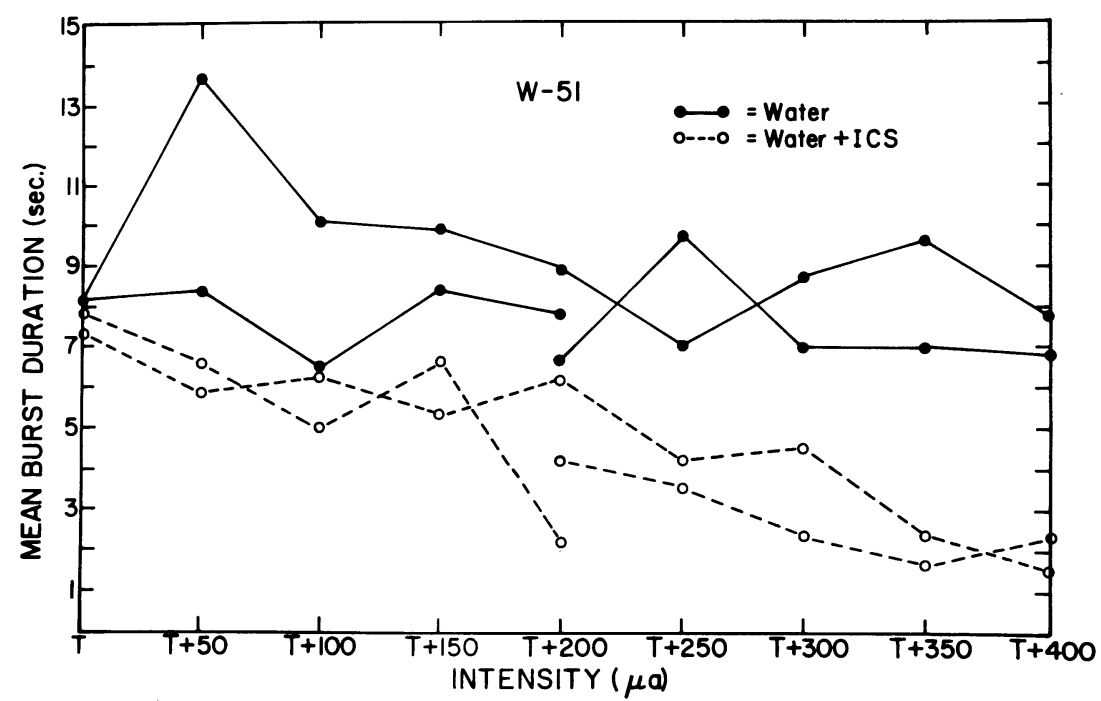

Figure 5. Burst duration (in seconds) for W-51 from threshold (T) to threshold plus $400 \mu \mathrm{A}(\mathrm{T}+400 \mu \mathrm{A})$ for the water $(\mathrm{W})$ and water plus ICS $(W+I)$ components of the multiple schedule.

units excited in the lick response, there should have been a general increase in the burst measures in the present experiment. Although there was some facilitation, it is not clear why this was only seen at threshold intensities. Disruption of the lick response by the high-intensity ICS can be ruled out since the animals were still making multilick bursts (Figure 7).

It might be that the higher intensity stimulation blocked sensory input from the tongue. Ball (1967) has provided evidence that ICS to the LH area acts to block sensory information from the periphery. Hulse (1967) has argued that the number of tongue tactile receptors stimulated by the water drop determines the size of the ensuing burst of licks. Thus, a blockage of this sensory input by the ICS could account for the decrease in burst size.

Lick rate within the postreinforcement burst was not affected by any of the experimental manipulations. This differs from White and Wayner (1972), who reported that rats that were induced to drink by the ICS lapped faster at the water when the ICS intensity was increased. According to Wayner (1970), ICS should facilitate more motor units and translate into an enhancement of reflexive licking. It should be noted, however, that the animals in the present experiment were not stimulus-bound drinkers and that they were not lapping at a continuous water source as White and Wayner's animals were. 


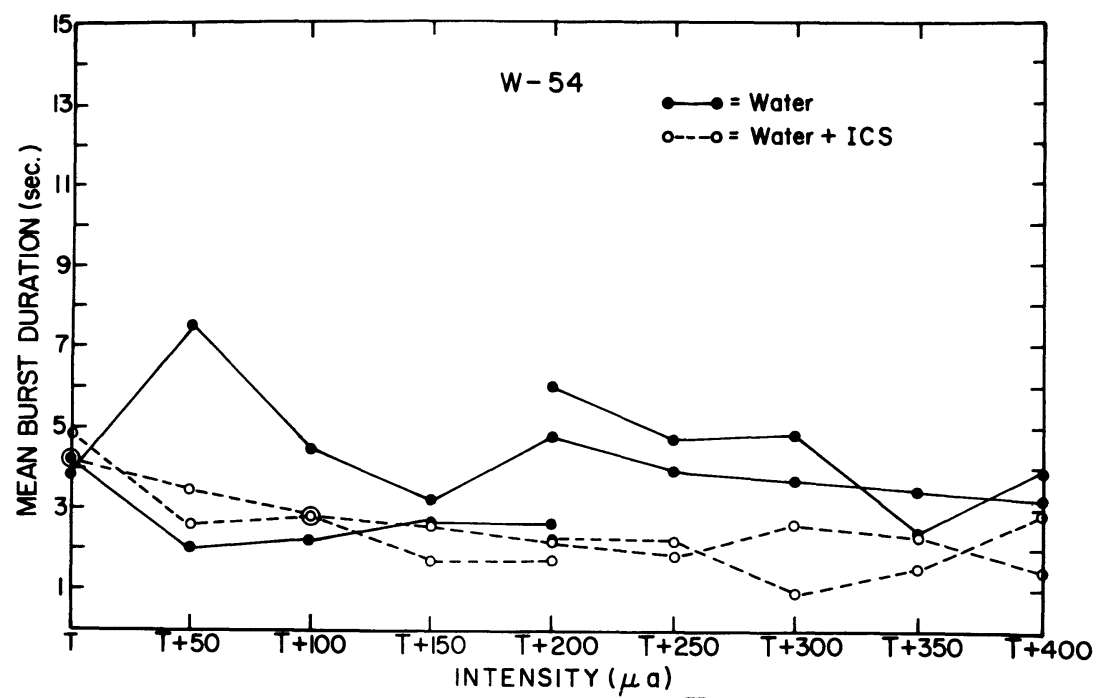

Figure 6. Burst duration (in seconds) for W-54 $(T+400 \mu \mathrm{A})$ threshold $(T)$ to threshold plus $400 \mu \mathrm{A}$ for the water $(W)$ and water plus ICS $(W+I)$ components of the multiple schedule.

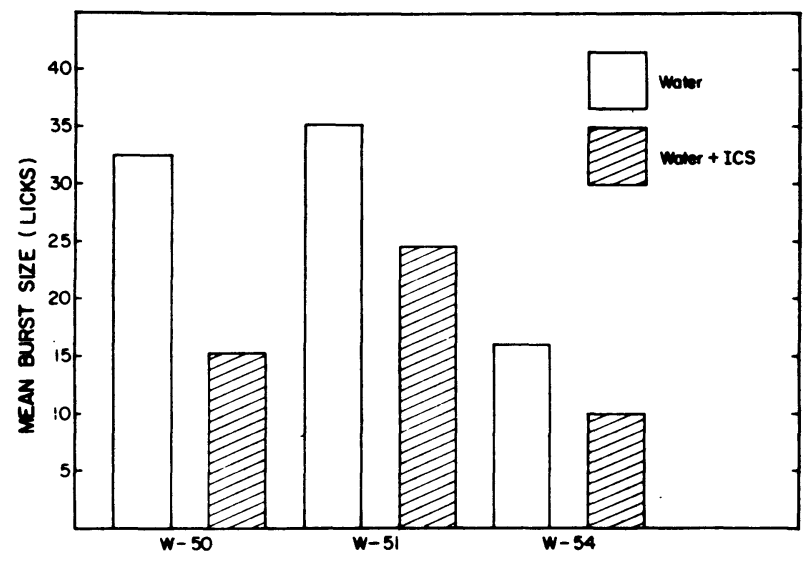

Figure 7. Mean licks per burst minus bursts of three licks or less for all animals in the water $(W)$ and water plus ICS $(W+I)$ components.

The measure of operant licking also suggests that suprathreshold ICS inhibits water licking. Again, at threshold levels there was a slight increase in responding, but at $\mathrm{T}+200 \mu \mathrm{A}$ there was a significant $(p<.05)$ decrease in responding. This is paradoxical when contrasted with responding for ICS alone. An increase in ICS intensity increased responding in the I component (Figure 8). Even more paradoxical is the significant $(p<.05)$ depression of responding in the $W$ component on days when it was paired with components that delivered ICS at $\mathrm{T}+200 \mu \mathrm{A}$ during the deprivation manipulation phase. Apparently, some aspect of the higher intensity stimulation was having a negative effect on the succeeding $\mathrm{W}$ component. This negative effect from the $\mathrm{W}+\mathrm{I}$ component could be explained by Ball (1967). Ball has proposed a rebound theory of rewarding brain stimulation. The ICS first acts to

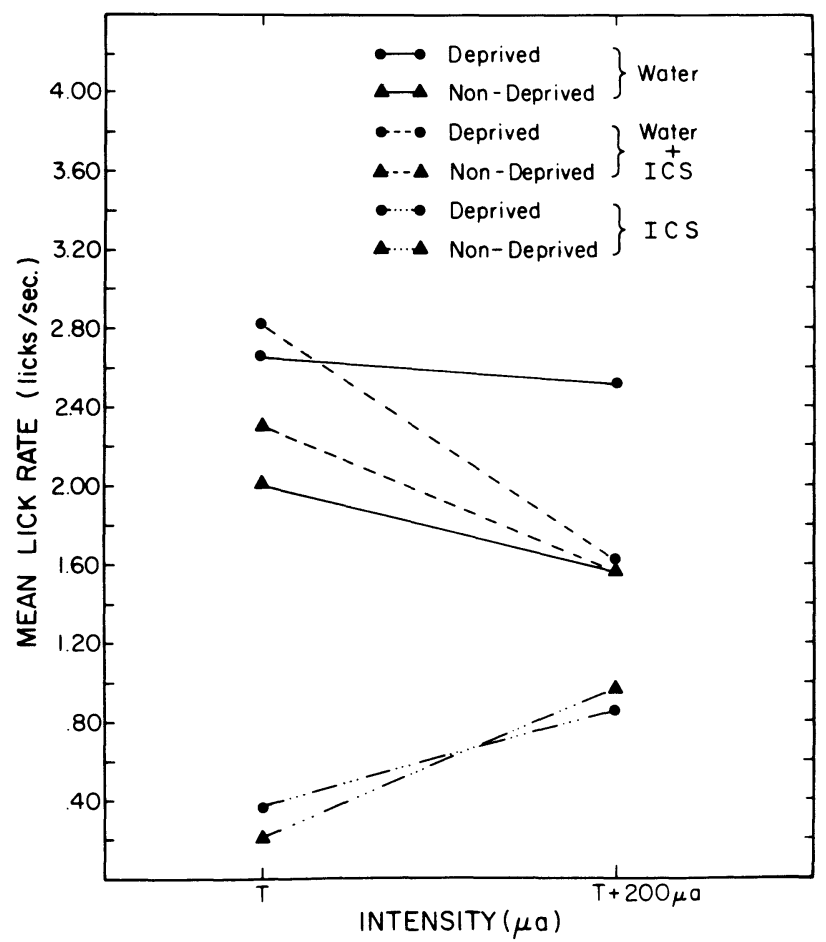

Figure 8. Mean nonburst lick rate (licks/sec) for all three animals at each level of deprivation and intensity, for each component of the multiple schedule.

block sensory input and then, after this blockage, there is an aversive rebound state that the animal attempts to alleviate by further self-stimulation. This aversive rebound state could account for the decrease in responding in the $\mathrm{W}$ component. The animal could not block this aversive state by more stimulation since he only got water for licking.

The data also do not appear to support an in- 


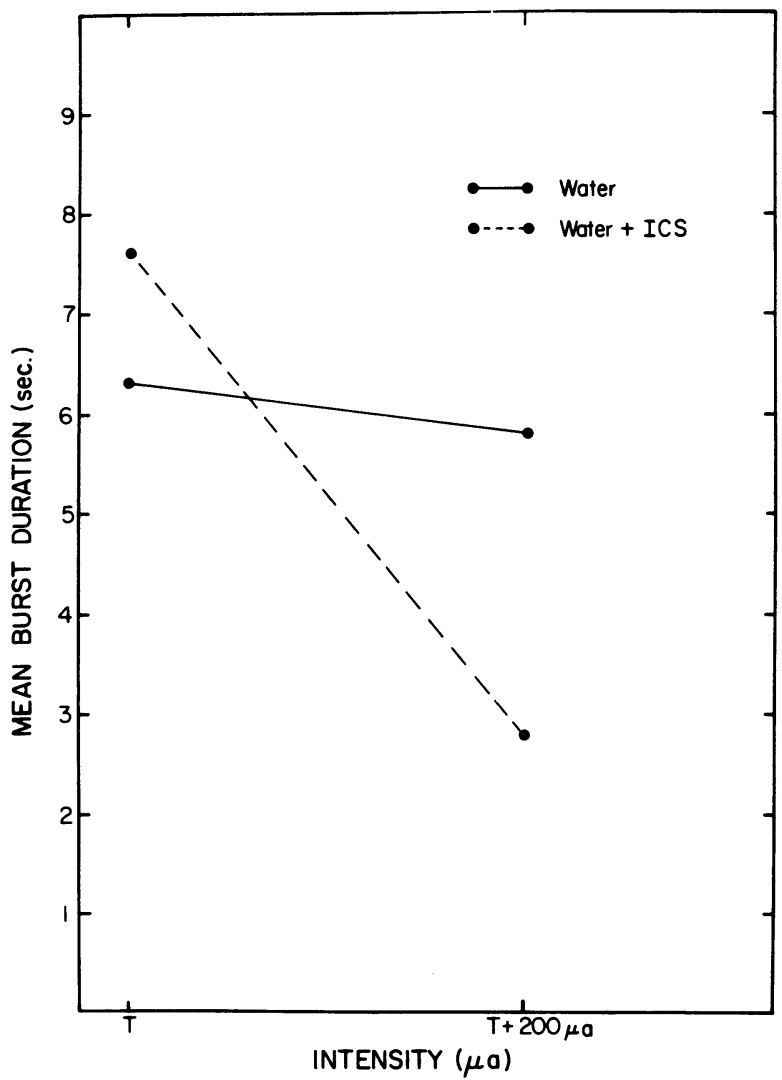

Figure 9. Mean burst duration (in seconds) for all three animals at each intensity in the water $(W)$ and water plus ICS $(W+I)$ components.

centive theory of rewarding ICS (1969). If responding were maintained by positive incentive stimuli arising from the ICS, responding should increase when ICS is combined with water, or certainly not decrease. The temporal relationship between the response and reinforcement delivery was precisely equated in the present experiment, as was the deprivation level of the animals. According to Trowill et al. (1969), responding for ICS and water should be qualitatively the same.

In conclusion, the use of the one-drop licking paradigm allowed an assessment of two theories of rewarding brain stimulation.

Wayner's (1970) motor excitability theory should predict an enhancement of reflexive licking when ICS is added to the animal's licking. The results of this experiment found in general a decrease in the size of the reflexive burst of licking following reinforcement delivery when ICS was added to water reinforcement.

An incentive theory of rewarding brain stimulation (Trowill et al., 1969) should predict that licking for water alone or ICS alone would be similar. This position should also predict an enhancement of operant (nonreflexive) responding when these two positive incentive stimuli are combined. The present experiment found that licking for ICS and water

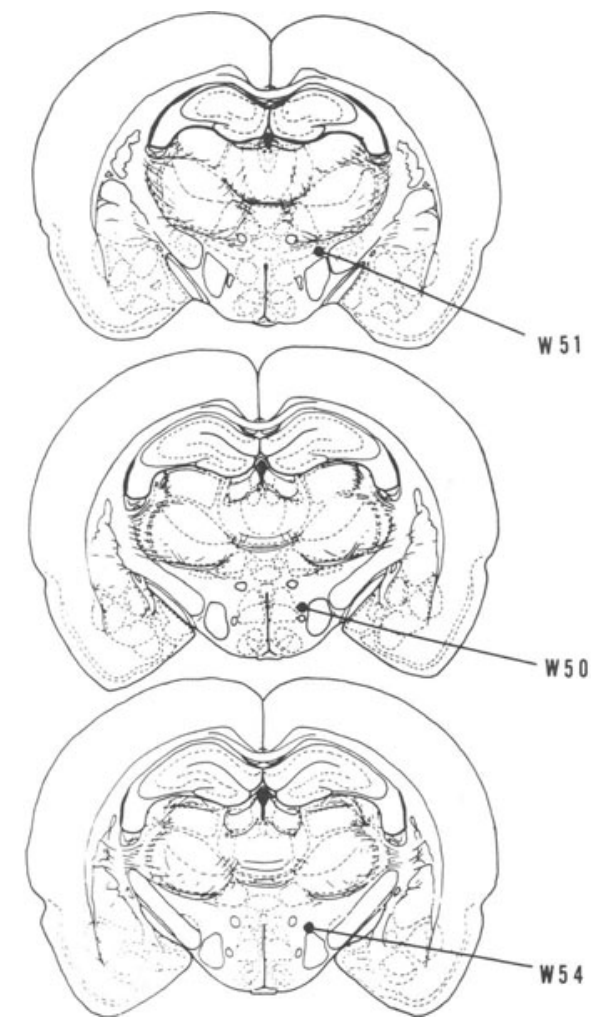

Figure 10. Electrode placements reconstructed on plates taken from the rat brain atlas of König and Klippel (1963).

was very dissimilar. Furthermore, the combination of ICS and water decreased the operant lick rate in this component of the multiple schedule.

\section{REFERENCES}

BaLl, G. G. Electrical self stimulation of the brain and sensory inhibition. Psychonomic Sciences, 1967, 8, 489-490.

Hulse, S. H. A precision liquid feeding system controlled by licking behavior. Journal of the Experimental Analysis of Behavior, 1960, 3, 1-3.

HULSE, S. H. Licking behavior of rats in relation to saccharine concentration and shifts in fixed ratio reinforcement. Journal of Comparative and Physiological Psychology, 1967, 64, 478-484.

Hulse, S. H., \& Suter, S. Emitted and elicited behavior: An analysis of some learning mechanisms associated with fluid intake of rats. Learning and Motivation, 1970, 1, 304-315.

KöNIG, J. F. R., \& KLIPPEL, R. A. The rat brain. Baltimore: Williams and Wilkins, 1963.

Trowill, J. A., Panksepp, R., \& Gandelman, R. An incentive model of rewarding brain stimulation. Psychological Review, 1969, 76, 264-281.

WAYNER, M. J. Motor control functions of the lateral hypothalamus and adjunctive behavior. Physiology and Behavior, 1970, 5, 1319-1325.

White, S. D., \& WAYNER, M. J. Lick rate during lateral hypothalamic electrical stimulation in the rat. Physiology and Behavior, 1972, 8, 771-772.

(Received for publication August 2, 1976; revision accepted October 27,1976 .) 